\title{
Staphylococcus pettenkoferi
}

National Cancer Institute

\section{Source}

National Cancer Institute. Staphylococcus pettenkoferi. NCI Thesaurus. Code C128548.

A species of facultative anaerobic, Gram-positive, nonmotile, nonspore-forming, coccusshaped bacteria in the phylum Firmicutes. This species is coagulase-negative and is a commensal organism on the skin of healthy humans but may cause infections in immunocompromised individuals. 